\section{Retrograde jejunogastric intussusception caused by a migrated gastrostomy tube}
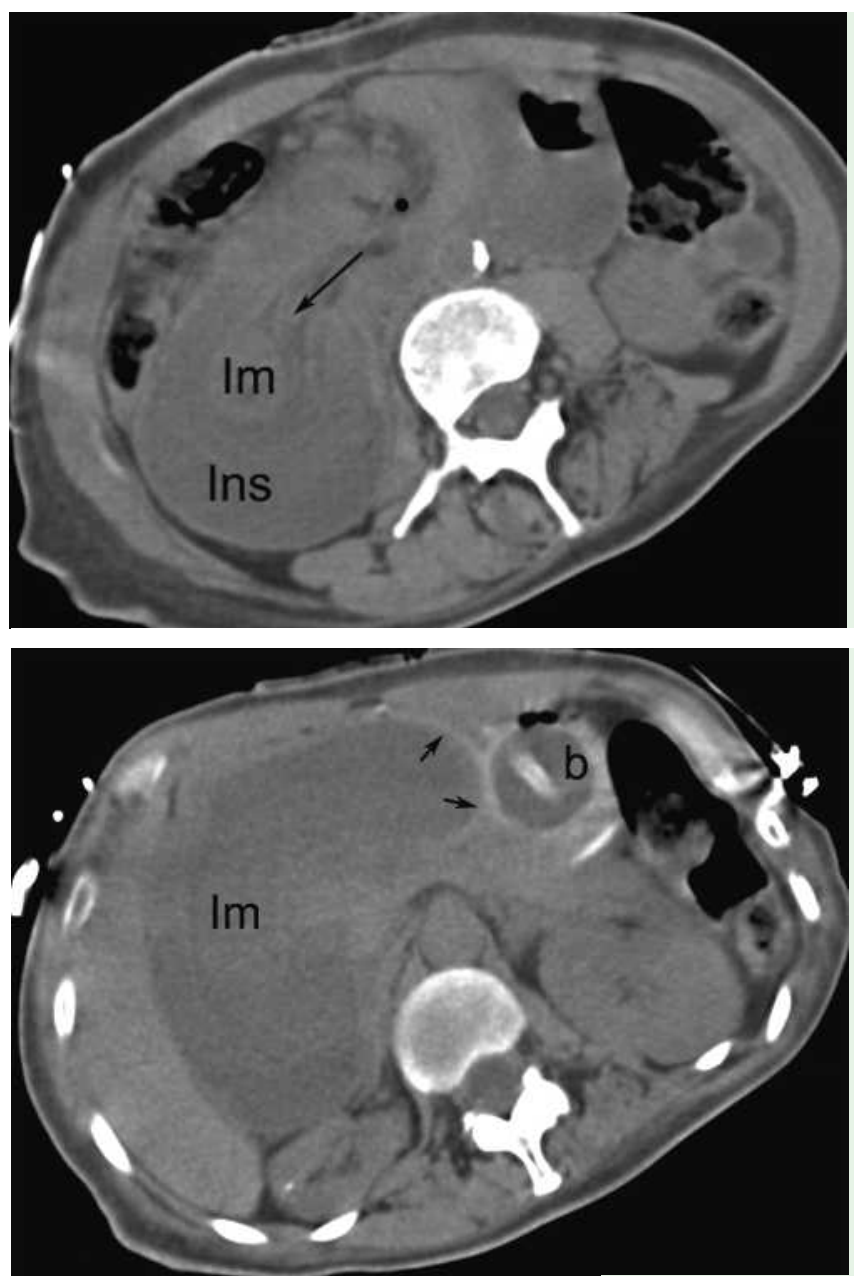

Fig. 2 A slightly more caudal computed tomographic image than that shown in - Fig. 1. The intussusceptum can be seen faintly, more cranially. The edge of the intussusception (arrows) is contrasted with the oral contrast in the stomach. Note the gastrostomy balloon (b).

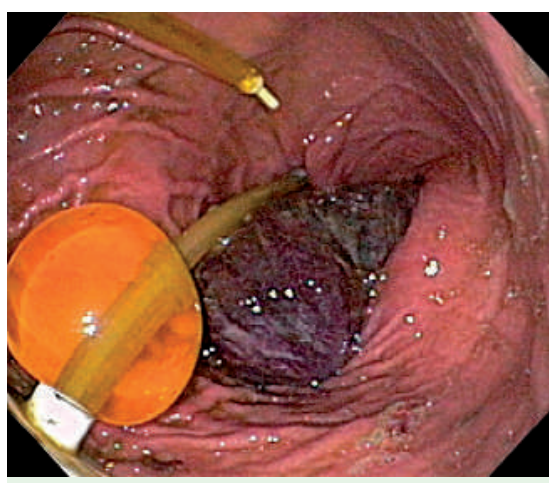

Fig. 3 Endoscopic view from the proximal stomach, showing a gastrostomy tube coiled up within the body. Note the distance between the entry site and the balloon. A large purple mass of intussuscepted bowel is seen extending from the antrum.
A 43-year-old woman presented to our hospital with emesis and coffee-ground output from the gastrostomy tube that she had had placed by interventional radiology 1 year before. On arrival, her heart rate was 140 beats per minute and her systolic blood pressure was $50 \mathrm{~mm} \mathrm{Hg}$. Laboratory testing showed her white blood cell count to be $30 \times 10^{9} /$ $\mathrm{L}$ and her lactate was $3.8 \mathrm{mmol} / \mathrm{L}$. A gastrostomy was in place, without any external fixation device. Computed tomography showed a mass containing small bowel, which was thought to be a jejunogastric intussusception ( Fig. 1,2). Upper endoscopy revealed the gastrostomy, with its balloon inflated, approximately $10 \mathrm{~cm}$ from the gastric entry site (৫ Fig. 3), and a large, purple, friable mass emanating from the pylorus ( Fig. 4,5). Because the intussusception could not be reduced endoscopically, an emergency laparotomy was performed and a retrograde jejunogastric intussusception with ischemia was found. The bowel was dusky but was not perforated (ه Fig. 6). We resected $20 \mathrm{~cm}$ of jejunum and pathological examination revealed hemorrhagic coagulative necrosis and acute inflammation. The patient made an uncomplicated recovery postoperatively. Gastrostomy tubes have been associated with rare complications such as bleeding, infection, peritonitis, and migration through the gastric wall [1]. Jejunogastric intussusception, first described by Bozzi in 1914 [2], is a rare complication of gastroenterostomy, and around 200 cases have been reported worldwide [3]. Only a few cases have been reported following the placement of percutaneous gastrostomy tubes $[3,4]$. Presenting symptoms are mainly obstructive, with epigastric pain and nausea with emesis [3]. The pathogenesis of jejunogastric intussusception associated with feeding tubes is incompletely understood. Some have suggested that the inflated balloon migrates into the small bowel, and that tube repositioning without balloon deflation intussuscepts the small bowel into the stomach [5]. In this case, the emergency department notes indicated that nursing staff had pulled on the gastrostomy after the emesis began without first deflating the balloon. Although rare, jejunogastric intussusception should be considered in patients with feeding tubes who present with gastrointestinal bleeding or obstruction. 


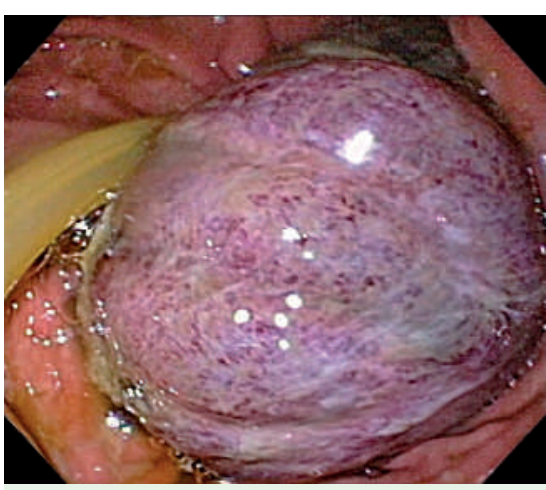

Fig. 5 A close-up endoscopic view of the friable, dusky, intussuscepted small bowel, which is covered with gelatinous exudate.

\section{Acknowledgment}

We would like to thank Dr. Michael Hull from the Department of Pathology and Immunology at Washington University School of Medicine for his assistance with the pathology specimens.

Endoscopy_UCTN_Code_CPL_1AH_2AI

L. Pelosof ${ }^{1}$, D. A. Ringold ${ }^{2}$, E. Kuo ${ }^{1}$, S. Bhalla ${ }^{3}$, R. Whinney ${ }^{1}$,

\section{G. R. Zuckerman ${ }^{2}$}

1 Department of Surgery, Washington University School of Medicine, St. Louis, Missouri, USA

2 Department of Medicine, Washington University School of Medicine, St. Louis, Missouri, USA

3 Department of Radiology, Washington University School of Medicine, St. Louis, Missouri, USA

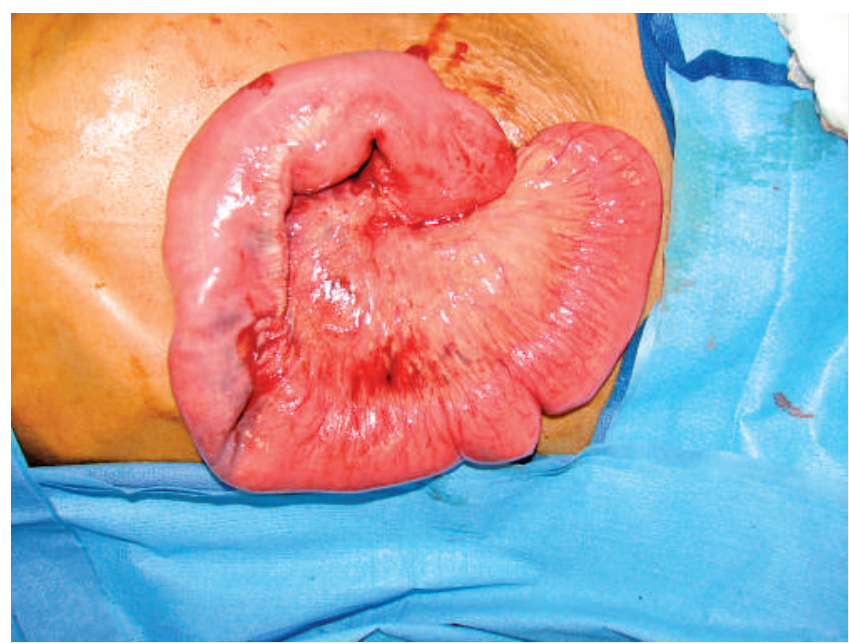

Fig. 6 A segment of jejunum is mobilized intraoperatively. Patches of pale, dusky serosa are widespread on the left, and focal, transmural necrosis was identified in the histologic sections of this portion of the intestinal segment.

\section{References}

1 Nicholson FB, Korman MG, Richardson MA. Percutaneous endoscopic gastrostomy: a review of indications, complications and outcome. J Gastroenterol Hepatol 2000; 15: $21-25$

2 Bozzi E. Annotation. Bull Acad Med 1914; 122: $3-4$

3 Archimandritis AJ, Hatzopoulos N, Hatzinikolaou $P$ et al. Jejunogastric intussusception presented with hematemesis: a case presentation and review of the literature. BMC Gastroenterol 2001; 1: 1

4 Gasparri MG, Pipinos II, Kralovich KA et al. Retrograde jejunogastric intussusception. South Med J 2000; 93: 499-500

5 Lamont AC, Rode H. Retrograde jejuno-duodeno-gastric intussusception. Br J Radiol 1985; 158: $212-213$

\section{Bibliography}

Dol $10.1055 / \mathrm{s}-2007-966579$

Endoscopy 2007; 39: E262 -E263

(c) Georg Thieme Verlag KG Stuttgart · New York . ISSN 0013-726X
Corresponding author

\section{Ringold, MD}

Department of Medicine Division of Gastroenterology Washington University School of Medicine 660, South Euclid Avenue

Campus Box 8124

St. Louis

Missouri 63110

USA

Fax: +1-314-454-5107

dringold@im.wustl.edu 